Robert A. Gross, MD, PhD, FAAN

Editor-in-Chief, Neurology ${ }^{\circledR}$

\section{Postmortem verification of MS cortical lesion detection with 3D DIR}

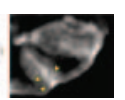

Single-slab 3D DIR (double inversion recovery) and 3D FLAIR images of 56 matched fresh brain samples from 14

patients with chronic multiple sclerosis (MS) were acquired at 1.5 T. DIR is a useful technique to visualize cortical lesions in MS; many lesions are still missed, but those that are detected are likely actual lesions in terms of histopathology.

Seep. 302

From editorialists Ciccarelli \& Chen: "Although DIR MRI is a recent innovation, it has provided important insights into the occurrence of cortical pathology in all subtypes of MS and the association of cortical pathology with clinical disability." See p. 296

\section{Association of MRI metrics and cognitive impairment in radiologically isolated syndromes $\mathbb{a}$}

The authors assessed the cognitive performance in 29 subjects with radiologically isolated syndromes (RIS) and 26 patients with relapsing-remitting MS (RRMS). Nineteen RIS subjects, 26 RRMS patients, and 21 healthy controls also underwent quantitative MR assessments. These findings emphasize the importance of accurate neuropsychological testing and quantitative MR metrics in RIS subjects suggestive of MS. See p. 309

\section{A randomized trial of decision-making in asymptomatic carotid stenosis $\llbracket$ Pt}

This study compared responses to different presentation formats including absolute, annualized, event-free, qualitative, and relative estimates. Approximately two-thirds of subjects exposed to relative or qualitative estimates and approximately one-third of those exposed to other formats chose surgery. Presentation format (information framing) strongly determines patient decision-making in asymptomatic carotid stenosis.

See p. 315; Editorial, p. 298
AMERICAN ACADEMY OF NEUROLOGY。

\section{Linking MRI to daily life experience: The example of poststroke depression}

MRI examinations were performed in 15 stroke patients, followed by computerized ambulatory monitoring of daily life experiences over 1 week. Mobile technologies are a powerful tool for understanding the direct relevance of neuroimaging results in patients' daily lives and open the way to new advances in neurology.

See p. 322

\section{Comment: Mobile technology in neurology}

Concerning broader questions raised by this research such as therapeutic implications, it seems that we have only begun to explore the frontiers of mobile technologies in health care.

See p. 323

The incidence of $\mathrm{MCl}$ differs by subtype and is higher in men: The Mayo Clinic Study of Aging :

This study examined 1,450 subjects who were cognitively normal at baseline of whom 296 developed mild cognitive impairment $(\mathrm{MCl})$. The standardized incidence rate was 63.6 overall and was higher in men than women. Differences in incidence rates by clinical subtype and sex suggest it is important to examine risk factors for $\mathrm{MCl}$ in men and women separately.

See p. 342; Editorial, p. 300

\section{Functional integration of parietal lobe activity in early} Alzheimer disease

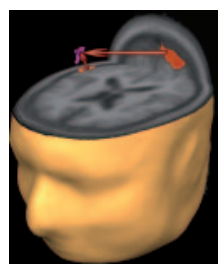

This study analyzed fMRI data using connectivity analyses in 18 patients with mild cognitive impairment and 18 controls. Connectivity loss involving the posterior cingulate gyrus was associated with increased neural compensation and memory decline. Connectivity analysis provides a tool to better understand Alzheimer disease and to evaluate treatment strategies.

See p. 352

NB: Resident \& Fellow Clinical Reasoning: "A 33-year-old woman with severe postpartum occipital headaches" appears in print this week (see p. 366). To check out other Resident \& Fellow submissions, point your browser to www.neurology.org and click on the link to the Resident \& Fellow Section.

Podcasts can be accessed at www.neurology.org 


\title{
Neurology
}

\author{
Spotlight on the January 31 Issue \\ Robert A. Gross \\ Neurology 2012;78;295 \\ DOI 10.1212/WNL.0b013e3182455734
}

This information is current as of January 30, 2012

\section{Updated Information \&} Services

Permissions \& Licensing

Reprints including high resolution figures, can be found at: http://n.neurology.org/content/78/5/295.full

Information about reproducing this article in parts (figures,tables) or in its entirety can be found online at:

http://www.neurology.org/about/about_the_journal\#permissions

Information about ordering reprints can be found online:

http://n.neurology.org/subscribers/advertise

Neurology ${ }^{\circledR}$ is the official journal of the American Academy of Neurology. Published continuously since 1951, it is now a weekly with 48 issues per year. Copyright Copyright $@ 2012$ by AAN Enterprises, Inc.. All rights reserved. Print ISSN: 0028-3878. Online ISSN: 1526-632X.

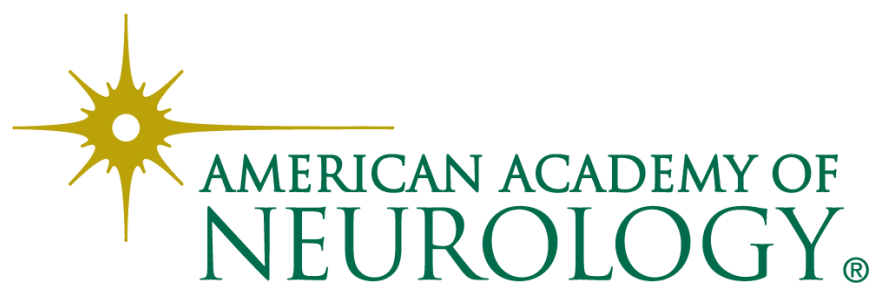

